\title{
К ВОПРОСУ О СОВРЕМЕННОЙ ПРОБЛЕМАТИКЕ В ПОСТРОЕНИИ СИСТЕМЫ УПРАВЛЕНИЯ ИННОВАЦИЯМИ В ОПОРНЫХ ВУЗАХ РЕГИОНОВ
}

\author{
(c) 2019 Колесников Александр Михайлович \\ доктор экономических наук, профессор \\ Санкт-Петербургский университет аэрокосмического приборостроения, Россия, Санкт-Петербург \\ E-mail:9843039@mail.ru
}

(c) 2019 Вагин Сергей Геннадьевич

доктор экономических наук, профессор

Самарский государственный технический университет, Россия, Самара

E-mail:vsg63@hotmail.com

В работе исследованы наиболее значимые вопросы, связанные с построением системы управления инновациями в опорных вузах регионов. Данное направление является актуальным в рамках формирования базы для развития регионов Российской Федерации опережающими темпами. В связи с этим цель работы - определение современной проблематики в построении системы управления инновациями в опорных вузах регионов.

Ключевые слова: опорный вуз, национальные проекты, бизнес-инкубатор, бизнес-акселератор, стартап, инновационный менеджент.

Будущее современных российских компаний зависит от их сотрудников. Многополярный меняющийся мир ставит бесчисленное количество вызовов всем организациям без исключения.

Централизация бизнеса в России вызывает опасения не только среди его владельцев, но и среди высших кругов власти. Централизация вызвана рядом особенностей, связанными с комфортностью ведения бизнеса и его большей экономической целесообразностью в ряде регионов. Однако зачастую в государствах с передовой экономикой такая централизация отсутствует. США, Германия, Китай имеют множество крупных экономических центров.

Наличие большого количества компаний способствует получению регионом дохода, который возможно направлять на развитие инновационно-инвестиционной инфраструктуры, что притягивает в этот регион ещё большие инвестиции и квалифицированные кадры. Эта цепочка образует замкнутый круг.

Многие регионы уже создали задел для того, чтобы стать экономическими центрами. Пока крупные игроки рынка не сильно стремятся начинать экспансию в регионы в связи с кризисными явлениями в российской экономике. При этом существенно также делать ставку на малый и средний бизнес.

Однако ни одна организация не начнёт своё развитие без квалицированных сотрудников.

Именно они будут двигать развитие компании. В то же время существенным звеном активного развития для бизнеса является его инновационная активность. Связать эти две составляющие способны опорные высшие учебные заведения регионов (опорные вузы).

Вопрос построения системы управления инновациями становится наиболее актуальным в контексте формирования базы для развития регионов Российской Федерации опережающими темпами. Опорные вузы регионов постепенно создают задел для такого развития, что требует от них внедрения передовых управленческих подходов и инструментария. Данный факт обуславливает цель работы - определение современной проблематики в построении системы управления инновациями в опорных вузах регионов.

Большие надежды в стране возлагаются на реализации приоритетных государственных программ и национальных проектов. Опорные вузы регионов должны играть ключевую роль в обеспечении высокого качества образования в России в соответствии с мировыми стандартами, делая его конкурентоспособным на мировом рынке, а также отвечать потребностям населения, которые регулярно меняются. Это создаст условия для выполнения государственной программы развития образования.

Система управления инновациями в опор- 
ных вузах регионов важна и в контексте реализации национальных проектов «Наука», «Образование» и «Производительность труда и поддержка занятости». Стимулирование инновационной активности опорными вузами также даст стимул к развитию цифровой экономики в Российской Федерации.

Ни для кого не секрет, что в основе наукоёмких отраслей стоит человеческий капитал. Именно ставка на человеческий капитал, который стал двигателем наукоёмких отраслей, позволила лидерам мировой экономики стать таковыми.

Современная практика показывает, что грамотное управление инновациями при этом сыграло не последнюю роль. Однако управление инновациями является весьма новым понятием для вузов Российской Федерации.

Инновации - весьма многогранное понятие. Обобщая его, можно заключить, что инновации - итоговый результат создания, освоения и внедрения новшества, которое способно удовлетворить потребности конкретного субъекта, с целью получения научно-технического, экономического или социального эффекта.

Инновации не могут существовать опосредованно. Задача вуза - ими управлять. Управление инновациями представляет собой процесс постоянного совершенствования различных сторон деятельности организации посредством создания, освоения и внедрения новшеств.

В целом, каждый вуз должен стремиться к стимулированию инновационной активности. Хотя зачастую небольшие региональные вузы с этой задачей справиться не способны. Опорные вузы регионов же аккумулируют большее количество ресурсов, позволяющее им стать драйвером развития своего субъекта страны.

Управление инновациями в вузе должно базироваться на научной составляющей и предпринимательстве. Научный потенциал опорных вузов важно распространять на предпринимательские инициативы. Результатом данных инициатив может стать создание малых инновационных предприятий.

Фундаментальная и прикладная наука всецело основывается на научно-исследовательской деятельности. При этом важным моментом в Российской Федерации стало внедрение научных достижений вузов в экономику страны. Существенно также использование научных разработок на практике и их последующая ком- мерциализация.

Эффективная система управления инновациями в российских опорных вузах не создана, что является основополагающей проблемой. Последовательность и структурированность этой работы - залог будущего успеха.

Бок о бок друг с другом при управлении инновациями находятся корпоративная стратегия и инновационный процесс. Они должны быть согласованы между собой. Инновационная стратегия отталкивается от корпоративной стратегии и формируется с акцентом на её достижение при помощи инноваций. Затем создаётся операционная модель, которая обеспечивает воплощение инновационной стратегии. Финальным этапом становится внедрение операционной модели в деятельность вуза [1].

Особой составляющей развития вузов должно становиться студенческое предпринимательство. При управлении инновациями этот момент является существенным. Любой вуз в той или иной степени наделяет своих студентов знаниями, умениями и навыками. Однако одной лишь теории не может быть достаточно для того, чтобы студенты становились предпринимателями. Барьерами для этого оказываются недостаток опыта вкупе с неуверенностью в собственных знаниях, неспособностью применить их на практике и отсутствием ресурсов.

Case study и геймификации обучения могут применяться различными категориями вузов. Это поможет студентам трансформировать их знания, умения и навыки в компетенции, при этом отрабатывая их на практике.

Опорные вузы обладают большим количеством ресурсов, поэтому они могут внедрять более передовые инструменты стимулирования предпринимательства среди студентов. Таким инструментом являются акселерационные программы. Посредством участия в них студенты получают менторскую поддержку, что позволяет постепенно их учебным проектам воплощаться в жизнь.

При организации акселерационной программы важно регулярно проводить встречи между студентами и менторами. Минимально эффективным являются встречи с периодичностью один раз в месяц. Оптимальным для детального анализа каждого из проектов на практике оказываются встречи один раз в одну-две недели. При этом важно, чтобы у закреплённого ментора было ограниченное количество участ- 
ников. Обычно ментору при условии его занятости, что актуально для среды преподавателей, удобно работать не более, чем с 5 проектами. Если количество студентов с проектами велико, то, конечно, возможно увеличить нагрузку, но от этого пострадает качество поддержки.

Преподаватели могут являться менторами проектов студентов. Здесь существенно провести параллель при нагрузке, её оплате и влиянии этого на работу вуза в целом. Однако студентам может быть не так интересно работать постоянно лишь с одними преподавателями, которых они видят и слышат на лекциях и семинарских занятиях довольно часто.

Не все вузы имеют возможность привлечь к работе со студентами выходцев из бизнес-среды. Однако опорные вузы в этом аспекте имеют ряд существенных преимуществ. Эксперты, спикеры, менторы и просто высококвалифицированные специалисты могут быть выпускниками опорного вуза. Их можно пригласить в качестве нерегулярных спикеров на мероприятия в рамках акселерационной программы, также они могут выступать экспертами проектов. Качество выпускников и репутация опорного вуза могут быть существенным преимуществом в плане привлечения их к работе даже на безвозмездной основе. Опорные вузы могут также организовывать взаимодействие со специалистами региональных и федеральных организаций развития, например, Фонд содействия развитию малых форм предприятий в научно-технической сфере, Фонд развития интернет-инициатив, Агентство стратегических инициатив.

Наличие акселерационных программ не решает вопроса с недостаточностью финансирования для реализации проекта или невозможностью его получения студентами. Данная проблема решается через выделение грантовой поддержки студентам. Редкий вуз способен организовать фонд, который будет финансировать проекты. Опорные вузы же могут компенсировать отсутствие средств в этом направлении путём сотрудничества со специализированными федеральными организациями.

Одной из таких организаций является Фонд содействия развитию малых форм предприятий в научно-технической сфере. Взаимодействие с фондом позволяет помочь студентам наиболее полно подготовить их проекты к конкурсу. Основными программами организации являются «Умник», «Старт», «Развитие», «Интернациона- лизация», «Коммерциализация» и «Кооперация». Максимальный размер гранта составляет 25 млн. руб. Студенческим проектам наиболее подходит программа «Умник». Участники программы борются за получение гранта в размере 500 тыс. руб. на 2 года на развитие инновационного проекта.

Под реализацию проектов, для работы проектных команд могут потребоваться помещения. Это могут быть коворкинги или бизнесинкубаторы. Если в случае с коворкингами основой являются именно готовые рабочие места, то в бизнес-инкубаторе возможно предоставление бухгалтерских, юридических и консультационных услуг. Материально-техническая база опорных вузов регионов может быть достаточна для организации коворкингов или бизнес-инкубаторов. Однако это влечёт высокие финансовые затраты. Организация работы коворкингов или бизнес-инкубаторов опорными вузами регионов уместно при государственной или частной поддержке, а также их коммерциализации. При этом важно выстроить оптимальную политику коммерциализации, чтобы собственные студенты не отказывались от посещения коворкингов и бизнес-инкубаторов на территории своих же вузов.

Работу акселератора возможно транслировать на образовательный процесс. В таком случае подготовку выпускных квалификационных работ существенно строить на основе методов и инструментов, применяемых акселераторами. Выпускная квалификационная работа представляется на манер стартапа. Здесь важна менторская поддержка научного руководителя, а также презентации работы перед другими научными руководителями, студентами и при возможности приглашёнными экспертами для внесения конструктивных правок в проект.

Опорные вузы регионов генерируют большое количество качественных научных разработок. Для дальнейшего стимулирования движения в этом направлении важна его коммерциализация. Опорные вузы для этого могут позволить организацию малых инновационных предприятий.

Получение прибыли вузом от малых инновационных предприятий позволяет улучшать материально-техническую базу, а именно производственные участки, лаборатории и другие её аспекты. К тому же это способствует получению преподавателями и, возможно, студентами, 
занятыми в них, дополнительного дохода, что мотивирует к дальнейшему труду. При этом воплощение собственных научных разработок в реальность также является существенным стимулом к деятельности.

В целом, вместе с развитием малых инновационных предприятий на базе опорного вуза региона увеличивается его репутация, что позволяет привлечь к работе более высококвалифицированных специалистов и одарённых абитуриентов.

Важным аспектом в управлении инновациями в опорных вузах регионов является взаимодействие с бизнесом. От бизнеса должен идти постоянный запрос на специалистов и технологии, а вуз должен на них отвечать. Это касается как формирования среднесрочных и долгосрочных планов по обучению специалистов по традиционным направлениям обучения, так и работы в рамках создания краткосрочных программ обучения для бизнеса, в том числе программ повышения квалификации. Отдельным элементом работы может стать тесное сотрудничество с наиболее крупными организациями региона в контексте создания их корпоративных университетов.

Управление инновациями в опорных вузах регионов может не отличаться от управления инновациями в коммерческих организациях из бизнес-среды. Важно опираться в работе на квалифицированных сотрудников. Относиться к ошибкам стоит лояльно, но только если в основе них не лежит некомпетентность [2].

Уменьшение количества ступеней в иерархии вуза может быть осуществлено только за счёт сильного лидерства. Самоорганизованные команды работают слаженно только, когда двигаются в едином направлении. Руководство всецело должно ответственно подходить к результату. Атмосфера сотрудничества достигается только при готовности каждого к принятию личной ответственности [3].

Всё же дисциплина, открытая обратная связь не должны давать угасать готовности к экспериментам, а сотрудники должны чувствовать себя не под гнётом постоянной ответственности, ведь команда окажет всю необходимую поддержку.

Процесс построения системы управления инновациями в опорных вузах регионов во многом поступательный. Нельзя вмиг воссоздать все элементы. Опорные вузы принимают на себя вызовы, брошенные им современным миром. Совершенствование инновационной деятельности способствует расширению возможностей опорных вузов регионов. Трансформация образовательного процесса и научно-исследовательской деятельности становится необходима не только для стабильного развития конкретного вуза, но и всей страны в целом.

\section{Библиографический список}

1. Бланк С. Четыре шага к озарению: Стратегии создания успешных стартапов / Стив Бланк; Пер. с англ. - М.: АЛЬПИНА ПАБЛИШЕР, 2017.- 368с.

2. Инновации в России - неисчерпаемый источник роста [Электронный ресурс] / Центр по развитию инноваций McKinsey Innovation Practice, 2018. - 110 c. URL: https://www.mckinsey.com/ /media/McKinsey/Locations/ Europe\%20and\%20Middle\%20East/Russia/Our\%20Insights/Innovations\%20in\%20Russia/Innovations-in-Russia_ web_lq-1.ashx (дата обращения: 13.05.2019).

3. Адизес И. Демонтаж вертикали: как сделать Россию инновационной страной [Электронный pecypc] / Forbes, 2019. URL: https://www.forbes.ru/biznes/375429-demontazh-vertikali-kak-sdelat-rossiyu-innovacionnoystranoy (дата обращения: 13.05.2019). 